Article

\title{
Energy Efficiency Improvement in Non-Intensive Energy Enterprises: A Framework Proposal
}

\author{
José Rafael Lopes ${ }^{1, *}$, Salvador Ávila ${ }^{2}$, Ricardo Kalid ${ }^{3}$ and Jorge Laureano Moya Rodríguez ${ }^{1}$ \\ 1 Department of Chemical Engineering, Federal University of Bahia, Salvador-BA 40210910, Brazil; \\ jorgemoyar@gmail.com \\ 2 Department of Mechanical Engineering, Federal University of Bahia, Salvador-BA 40210910, Brazil; \\ avilasalva@gmail.com \\ 3 Center for Training in Science, Technology and Innovation, Federal University of Southern Bahia, \\ Itabuna-BA 45613204, Brazil; ricardo.kalid@gmail.com \\ * Correspondence: jrafael.lopes@gmail.com
}

Received: 22 March 2018; Accepted: 24 April 2018; Published: 16 May 2018

\begin{abstract}
Generalized renewable energy use and the implementation of energy efficiency are two promising solutions to face global environmental challenges and achieve sustainable development. Government and large enterprises are making efforts in this direction; however, there are bottlenecks to start energy efficiency projects especially in non-intensive energy enterprises (NIEs). The aim of this work is to discuss energy efficiency improvement (EEI) initiatives and analyses a framework proposal to improve the energy efficiency implementation in (NIEs). It was applied the theory of Barrier Model to Energy Efficiency to understand the gap between the levels of opportunities implemented, and what theoretically the industrial sector could achieve. It was found that behavior barriers are relevant to understand the efficiency gap and it is necessary to have an action plan to address them. The analysis has been carried out in the fertilizer industry and the preliminary results demonstrate the advantageous reduction of energy losses.
\end{abstract}

Keywords: energy efficiency; energy conceptual framework; operator behavior; barrier model

\section{Introduction}

Concerns about energy have been increasing due to the use of fossil fuels to supply economic growth and the environmental impact related to greenhouse gas emissions. These issues have generated uncertainty about sustainable development.

The generalized use of renewable energy and the implementation of energy efficiency seem to be promising solutions; therefore, governments and enterprises are making efforts to identify effective measures to improve energy saving in manufacturing processes.

In spite of managers having many concerns regarding production, clients, providers, quality etc.; energy performance needs to be included in their agenda. While energy intensive companies have seeking ways to embed energy management practices, non-intensive enterprises (NIEs) are limited in energy concerns. Besides the lack of knowledge and financial restrictions, little attention is given to energy if it represents a small part of the total cost.

A lack of knowledge about the principles of energy efficiency gets hard the establishment of priority criteria in daily operations [1,2]. Although the managers of the NIEs agree that energy efficiency improvement (EEI) is an important matter, it is not highlighted as a way to improve competitiveness and cost reduction, and decrease the possible damage to the company image. Since the principles are deployed in an EEI plan, some expensive actions would inhibit the implementation when only economic issues are analyzed. Therefore, subsidies or low-interest loans could accelerate the diffusion 
of EEI [3]. Voluntary agreements for EEI and reduction of energy-related greenhouse gas (GHG) by industrial sector is not uncommon. These agreements have been adopted in the EU, U.S., Canada, Australia, New Zealand, Japan, South Korea, and Chinese Taipei [4].

As a methodological support to companies about EEI, an energy audit is mentioned by earlier studies that includes the discussion of production procedures [5-7], and the implementation and maintenance of an energy management system (EnMS). These methods can help to map the energy flow in a process in order to improve its performance. An EnMS based on ISO 50001 requirements reflects the PDCA cycle as well as long term goals, energy policies, organizational infrastructure, assessments, continuous monitoring of performance, and legal requirements [8].

However, researchers are challenged to explain why a significant portion of the potential for improvement provided by existing methods, processes, and technologies to reduce energy losses remains unexplored despite the commitment by companies to improve performance through investment in technology. With regard to energy management, the difference between the actual level of energy performance and what could theoretically be achieved by the implementation of technologies and organizational practices is called the energy efficiency gap [9-12]. One of the ways used to explain the discrepancy between the optimal energy efficiency (EE) level and the current level in an EnMS is the barrier model to energy efficiency.

A barrier can be defined as a mechanism that inhibits a decision that appears to be both efficient and economical $[7,13]$. Several authors categorize barriers as structural, economic, organizational and behavioral or associated with the technical system, the technological regime, and the socio-technical regime $[9,10,14]$. Thollander et al. [14] stated that the socio-technical regime is greatly influenced by human factors as individual behavior, e.g., and less influenced by technological issues.

Most authors categorized the barriers and evaluated the importance of each one in sample of companies from several economic sectors or check the gains from interventions in the technical or technological regime. However, studies of the socio-technical regime for EEI in the industrial sector are scarce, mostly are focused on the households [15-18], and the interventions on behavioral change, due to methodological issues, have been ineffective [19].

EEI planned measures are almost exclusively technology-driven in the industrial sector however, organizational measures also have great potential when combined with internal energy management practices [20]. Moreover, most of the researches are based on engineering (input and output model) and the understanding of how internal practices are internalized in organizations is insufficient.

The purpose of this study is to discuss EEI initiatives and analyze a framework proposal to overcome the behavior barriers to EEI mainly in NIEs. The theory of barrier model to energy efficiency was applied to understand the gap between the levels of opportunities implemented, and what theoretically the industrial sector could achieve. There are some papers that analyze energy management and energy efficiency [21-24], but the great majority of measures for improving energy efficiency deals with technical concerns such as changing old equipment and devices, using renewable sources, etc., but research seldom takes human behavior into account, which has great influence on energy efficiency. It is important to underline that at this paper employs quali-quantitative methods instead of quantitative methods.

\section{Literature Review}

The scale of anthropogenic pressure on biodiversity and ecosystem services has caused environmental change that might be irreversible. According to the concept of planetary boundaries, humankind has already transgressed four planetary boundaries: climate change, change in the integrity of the biosphere (loss of biodiversity and extinction of species), change in the soil system, and change in biogeochemical flows (nitrogen and phosphorus cycles) [25-27].

It is virtually a consensus in the academic community that large amounts of GHG need to be cut to avoid increasing temperatures by more than $2{ }^{\circ} \mathrm{C}$ and consequently reduce the catastrophic results of global warming. As sources of energy production are mostly based on fossil fuels, heavy investments 
are required to alternative fuels (biofuels, hydrogen) and renewable energy (biomass, wind, solar, geothermal, etc.). However, the technology to generate the quantity of energy is not still available in terms of scale and stability, demanding more basic research and development [28-30].

Carbon capture and storage (CCS) technology, substitution of fossil fuels, renewable energy, and energy efficiency measures allocated to the end-use sectors are options to cut $\mathrm{CO}_{2}$ emissions [31]. As the potential technologies to reduce GHG emissions require long-term investments due to the difficulties to be developed, energy efficiency is important to provide a solution in the short and medium term. In addition, an effective management system could reduce the difficulty to identify and implement the necessary measures [32-35].

There are many opportunities in the industrial process to reduce loss and consequently save energy. The main energy consumption equipment include motors, heaters, furnace, dryers, coolers and other power facilities, HVAC systems, artificial lighting systems, and office automation equipment [36].

Energy balance, exergy analysis, and pinch analyses as techniques to identify energy conservation measures. Energy balance is the most acknowledged approach that permits to calculate heat losses, but not afford information on how to best transform energy. This can be done by exergy analyses that determine the useful work potential of a given amount of energy providing a performance evaluation of thermal and thermochemical systems [37,38]. Pinch analysis is a thermodynamic analysis of currents that should exchange heat and the determination of the region where heat exchange is restricted with the purpose to allocate devices in this region. This method has worthwhile use in energy intensive industry [39].

The implementation of an effective energy management system goes through a cultural and behavioral change. The structure of the energy culture needs to be understood and the behavior of energy users should be comprehended in order to define the strategies for action [40]. The interactions among cognitive norms (beliefs, understandings, motivations, etc.), material culture (heating technology, construction procedure, etc.), and energy practices (e.g., activities, processes) must to be studied [41]. Regarding support for effective cultural and behavioral change, it is known that there is a significant interest in implementation of energy conservation practices when they are supported by using of metering devices [42] and when top management are involved in the energy-related decision-making process [43].

The European Union published the standard EN 16001 with the intention to guide the whole implantation of an energy management system (EnMS), while ISO published ISO 50001 in 2011. These standards specify requirements to a general EnMS to allow the identification of significant energy consumption areas with the aim of planning reduction actions.

The focus of the standards is based on three specific points: use (qualitative aspect of energy, which also includes human behavior among others issues), quantity (quantity energy aspect that covers consume and its reduction) and energy efficiency (technological aspect associated to the balance of energy resource expended and the results obtained in a particular case) [44].

Energy management in any industry is desirable for financial, social, and environmental reasons. Financial reasons focus on profitability and the growth potential of the companies, while social and environmental reasons refer to benefits that companies, workers and society gain from an energy management program.

A broader adoption of the ISO 5001 can be more difficult when compared with ISO 9001 and ISO 14001, the quality and environmental standard. The quality requirements have an economic relationship with the products delivered. ISO 14001 demands behavioral change however, legal aspects induce the awareness to conform to all EMS procedures and requirement. ISO 50001 requests changes to achieve goals in a distant 2050, which probably can be reached just with heavy investment in technology, equipment, and devices. Yet, the energy scenery is a driver because there are severe risks to the biodiversity and ecosystem services, and consequently to humankind.

An energy audit is the next step once the decision to implement an EnMS was taken. This plays an important role in the identification of potential energy savings since it identifies high consumption 
areas and analyses potential energy efficiency measures based on technical and economic viability [4]. The energy audit can be carried out with a different scope of analyses according to the needs of the organization. According to [1], energy audits can lower some difficulties related to behavior, organization, and information and brings awareness to companies, highlights difficulties, and indicates opportunities for energy saving resulting from the adoption of EEI [45].

Energy programs such as industrial energy audit programs and long-term agreements are the most common ways to overcome barriers to energy efficiency in industry [46]. However, audits conducted by engineers tend to be more effective than audits conducted by the organizations in the industrial sector, indicating that audit quality also affects the barriers and, therefore, the rate of adoption of energy efficiency measures [47].

There are considerable technical potential measures available to improve industrial energy efficiency. Despite being economically favorable and technologically viable involving small technical risks, they are not applied. Several studies $[11,12,46,48]$ indicate that the GAP in energy efficiency is related to the discrepancy between the level of opportunities implemented and what could theoretically be achieved. The technological potential is often greater than the economic potential since economic evaluations include discount rates and take into consideration the opportunity cost. Thus, even investments where benefits outweigh the cost could be neglected $[49,50]$.

According to Sorrell et al. [13] the barrier model can explain the energy efficiency gap. A barrier is described as a mechanism that inhibits a decision or behavior which is both efficient and economically favorable. This can be categorized into market failure, nonmarket failure, behavioral, and organizational and these broad categories are presented in Table 1.

Table 1. Barriers to energy efficiency according to Sorrell et al. [46].

\begin{tabular}{cc}
\hline Category & Theoretical Barriers \\
\hline Market failure/market imperfection & $\begin{array}{c}\text { Imperfect information } \\
\text { Adverse selection } \\
\text { Principal-agent relationship } \\
\text { Split incentives }\end{array}$ \\
\hline Nonmarket failures/nonmarket imperfections & Hidden costs \\
& Access to capital \\
& Risk \\
& Heterogeneity \\
\hline Behavioral barriers & Form of information \\
& Credibility and trust \\
& Values \\
& Inertia \\
Organizational barriers & Bounded rationality \\
\hline & Power \\
& Culture \\
\hline
\end{tabular}

Hiring ESCOs (energy services companies) is a solution in order to deal with these barriers [46]. These are engineering firms specializing in promoting energy and water efficiency at their customers' facilities. They develop services to identify opportunities; evaluate technical, environmental, and financial solutions; develop and implement projects and propose economic and tariff guidelines by means of direct contracting or by risk contract.

Government or voluntary programs, such as the Australia's Greenhouse Challenge, Canada's Industry Program for Energy Conservation, Finland's Action Program for Industrial Energy Conservation, and France's Voluntary Agreements on Carbon Dioxide Reductions are other common ways to overcome barriers to energy efficiency in industry [51]. Energy audits are also a useful tool; however, engineered audits tend to be more effective than audits performed by industry associations, 
which indicates that the quality of the audit also affects the barriers and thus the rate of adoption of energy efficiency measures.

Regarding to actions to overcome the barriers we have to consider the fact that measures for improvements in energy efficiency are almost exclusively technology oriented. One way to develop and improve energy management, both theoretically and practically, is to explore the socio-technical approach [20].

The socio-technical approach indicates that the organization is a complex system, in which the technical system (technology and tasks) interacts with the social system (organizational structure and attributes of workers in terms of attitudes, skills, values, etc.). These should be considered together and converged to provide the best performance for the organization [52]. As a result, the behavior of people towards work depends on the content of the tasks, because of the duties and feelings related to them. Responsibility, autonomy, achievement, recognition, and others, are essential for the individual improvement or reduction in pride, satisfaction, and energy for their work [53].

Bostrom and Heinen [54] stated that designers do not take into account the strong association between changes in the technical system (tasks or technology) and the impacts in the attitudes, motivations, and the interpersonal behavior of the individuals when they propose any change. Thus, a human reliability assessment can help to prevent failures after the changes have been done.

Human reliability indicates how reliable a worker will perform a task correctly or without an error. Additionally, human reliability assessment (HRA) aims to calculate probability of human error for a specific type of task [55].

According to human reliability research, there are principles to guide human action when a new technology-oriented measure is implemented. They state that people are fallible, situations of error are predictable and events can be prevented by understanding the reasons why errors occur. These reasons could be influenced by the design and layout of work systems, equipment interfaces, and the environment. Furthermore, people will find the easier way of doing things, even if it is riskier and human emotion, thought, performance, and attitudes are strongly influenced by the situation or context [56-58].

Considering these principles, Embrey [57] presents four approaches used to analyze, predict, and reduce human error in industrial systems. The first is the traditional approach to safety engineering and the second one uses human factor engineering/ergonomics (HFE/E). It emphasizes the mismatch between human capabilities and the demands of the system as the main source of human error. The third approach, cognitive systems engineering (CSE), introduces a modern method based on cognitive psychology that directs studies to better detail how people acquire information, process it internally, and use it to guide behavior. The fourth approach, from a CSE perspective, assumes that human error control also needs to consider the impact of management policy and organizational culture extending the analysis to the field of the organizational behavior [59].

\section{Methods}

The study focuses on the framework to overcome the barriers to EEI mainly in the socio-technical regime, addressing the following research questions: First, the study discusses initiatives to identify analyses and implement EEI measures, the theory of barrier model to energy efficiency, what factors constitute barriers, human reliability and how human behaviors are associated with this issue. Next, the study investigates how a framework can help non-intensive energy enterprises to overcome the difficulties through a systematic framework in order to reach appropriate energy efficiency implementation.

The framework was partially implemented in a fertilizer industry and it was used the study case method to discuss and reveal the framework effectiveness and the possible improvement opportunities. The study is also based on a literature review to know how industrial energy efficiency is being improved. 
As mentioned before, there is an untapped potential to improve industrial energy efficiency and the major model used to explain the discrepancy between the opportunities implemented and what could be reached is the barrier model. Nonetheless, most research on how to overcome the barriers concentrate on policy, economic, and technological approaches. Studies of a socio-technical approach are scarce.

It was discussed the STS theory and aspects of human reliability, the approaches used to analyze, predict, and reduce human error in industrial process in order to propose a conceptual socio-technical framework. Subsequently, it was verified the suitability of the framework through a case study from a fertilizer company.

The intention of case study is to present the results achieved by the work carried out and to discuss the procedures used based on the framework.

\section{Conceptual Framework}

As technology-oriented investment is usually the main measure used to EEI, not all organizations are able to make large investments due to budget restrictions. An effective way to improve management systems without requiring much capital is to invest in good practices that can be facilitated with the development of a specific technical culture. However, it takes time, effort, and often a hard breaking down of long-established patterns. Thus, it is recommended to start with the behavior changes of people and groups to speed up the cultural change.

In this study, it was assumed that there are four elements enable a company to deliver results: people, organizational structure, technology, and leadership as shown in Figure 1. All these elements are under pressure from the interested parties and external environment.

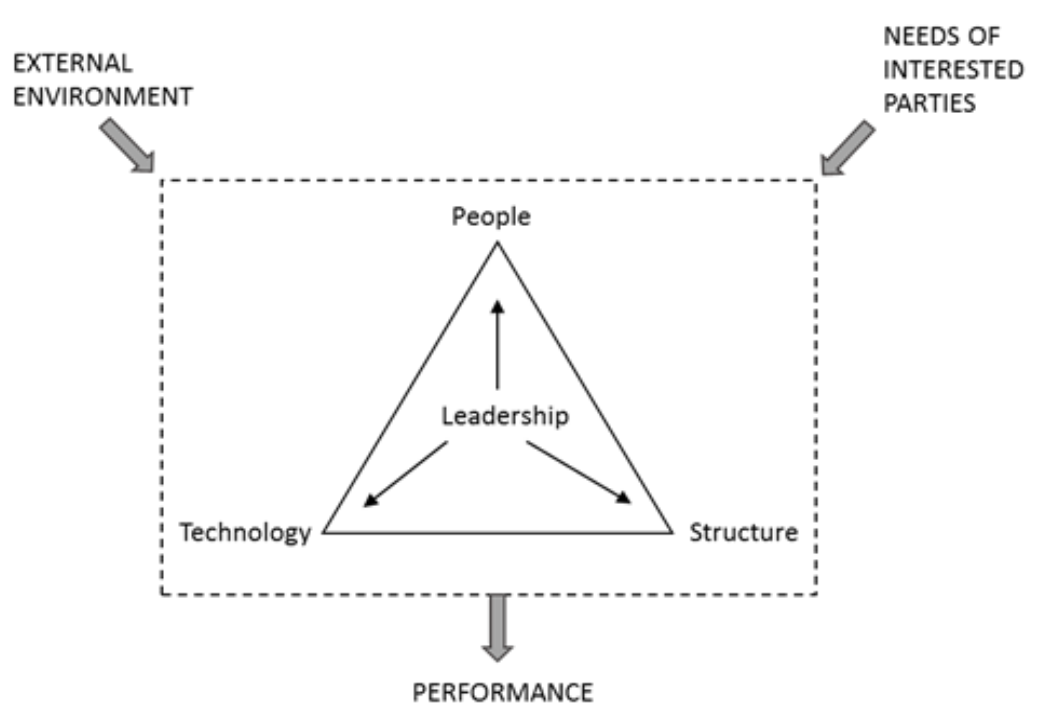

Figure 1. Elements influencing organizational performance.

The existence of the organization would be impossible without people, who consist of individuals and groups and make up the social system of the organization. People are dynamic in nature and interact and influence each other. The structure in an organization defines the roles, positions, and relationships of people; the division of labor; and aspects of responsibility and authority. Technology provides the economic and physical resources (e.g., machines, tools, and methods) allowing people to carry out their activities.

The key factor in an organization's management is the leaders. Through planned and coordinated actions, they influence the other elements. The role of leaders can be simplified into two aspects. The first is routine management, which comprised of the set of processes that keep the elements of people and technologies functioning properly. The most important aspects of routine management 
include production planning, budgeting, organization, control, and problem solving. The second role is strategic leadership, which includes processes to define the future of the organization, its values, and norms to allow changes to adapt to external circumstances that change significantly.

Leadership commitment is the first step toward implementing effective change in performance improvement. A truly effective change starts with top management demonstrating the behaviors they wish to be followed and to ensure the other three elements being balanced.

Based on the theoretical review, Figure 2 presents a cognitive map that should lead workers to develop a behavior that results in better organizational performance.

The interaction of the individual with all the elements shown in Figure 1 begins with the perception of reality through the senses. Perception is a relevant component of the individual's behavior, since it influences different interpretations or visions of the same event, and errors of perception can be serious and lead to irreversible damage. There are factors that influence the perception and for something to be perceived it should attract the attention. The role of our attention is to act as a filter, choosing what is most relevant, and this filter allows the brain to choose two routes. The first is the habit path, when the brain identifies a trigger of familiar situations and automatically starts activities memorized without conscious thought or with little attention to the process. Behavior is guided by pre-programmed instructions developed by practice or experience and is less dependent on external conditions. The response time to perceive information is fast because all this process is automatically carried out by mental synapses consolidated by systematic repetition.

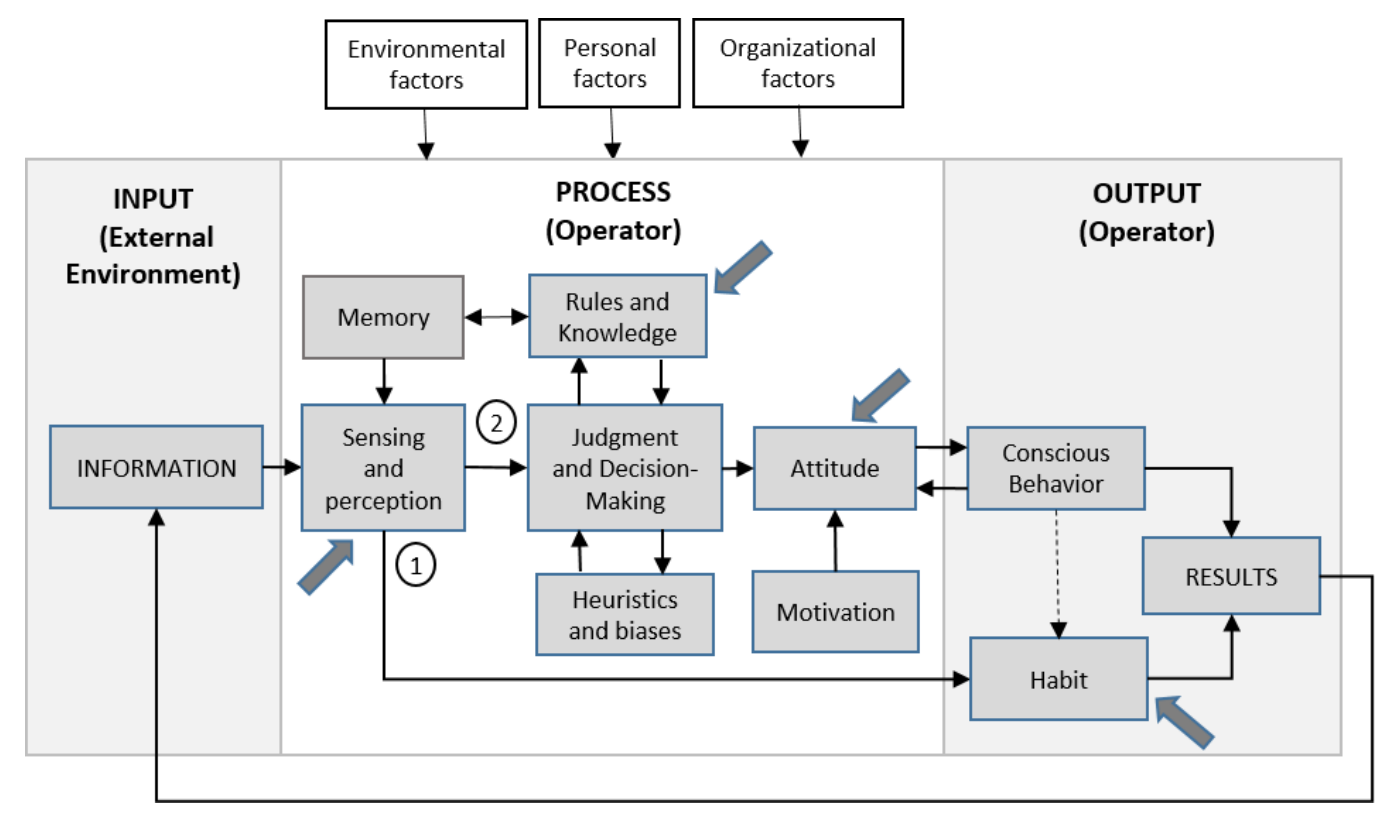

Figure 2. Cognitive map of operator behavior based on [60].

The habit path is effective because it is anchored in human skills. Errors resulting from this are due to lapses in attention caused by the variability of the human condition itself or by not looking for changes in external conditions. This means a person may be so focused on a particular task that important information in the workplace is ignored.

The second route is the rational and conscious one. After the target is perceived, the judgment process is performed for decision-making and attitude formation. The brain analyzes whether the information perceived corresponds to knowledge or a rule previously learned and stored in the memory. Besides, this process is influenced by shortcuts and distortions also called heuristics and biases. Therefore, the effectiveness of the conscious path is lower and the chance for error increase a lot 
and represent roughly $75 \%$ of all error in an industrial plant [61]. Errors due to this path are mistakes and violations resulting from activities of observing, interpretation, planning, and execution [62].

Attitude is an assessing statements regarding objects, people or events [63], and these statements are a result of our learning process and experiences with situations and people. Attitudes are important to organizations because of their components that lead to a specific behavior and because it can be changed by motivational practices.

The last step of the map represented in Figure 2 is the desired result. This will happen if there are not errors or deviation in the rational or habit path. Nevertheless, when a new task is being assigned, it is performed at the conscious level and the learning may not last over time. Definitive learning takes place when conscious behavior becomes automated by passing into the sphere of the unconscious and becomes a habit.

The proposed conceptual framework in order to overcome barriers to EEI in a socio-technical regime is illustrated in Figure 3. This aims at planning actions in the scope of perception, rules, and knowledge, in attitudes and in habit as indicated by arrows in Figure 2.

In the first step, it is necessary to make an assessment to identify the behavior associated to EEI. quality (e.g., brain storm, flow chart, Ishikawa diagram, Pareto diagram) and human factors and ergonomics (e.g., task analysis) tools can be used. It is vital the contribution of the people involved with the process such as the supervisor or the operators, as well as the support of a neutral person such as a researcher/consultant or a technician from another area. The identification of critical tasks/behaviors must be effective and two conditions need to be met: it should be measurable and have a significant impact on performance.

The second step is to set up a new standard, which is divided into three sub-steps described below.

(i) Change perception: as the reality perceived by people is more important than what is real itself, the knowledge about the team brain preference helps to better define communication strategies and improve the desired perception. An easy tool is to determine if the team profile is majority relational, experimental, analytical, or practical [64]. In addition, a survey should be carried out to measure the attitudes level of employees. This information shows whether employees will be indifferent or engaged with the proposed changes.

If the proposed change is not in line with employee attitudes, cognitive dissonance will occur [59]. This can be minimized if there is an acceptable justification or a reward system. Therefore, statements called 'reasons for people to care' (RPC) need to be presented in order to generate motivation and create a connection between the daily tasks and the wanted performance. Unfortunately, most of the change process as well the job training takes into account only the rational aspects without an emotional link. Thus, the RPC is better communicated using storytelling, symbols, and metaphors.

Moreover, according to the theory of expectation [59], employees will do the minimum necessary to remain employed. They will rationally ask the following questions: If I try my best, will I be recognized in my performance evaluation, generating a reward that will be good for me? This reinforces the argument that recognition is one of the major induction factors of employee satisfaction and engagement in order to create an emotional link with the team.

(ii) Define the future behavior: once the task/critical behavior has been identified, a functional analysis is performed to identify the antecedents or triggers (A), the behavior (B) and its consequences or rewards $(C)$ or-simply_ $A B C$ analysis [65]. This is based on the theory of learning and operant conditioning, where antecedent and consequent environments are vital for the understanding, prediction, and modeling of human behavior in organizations.

After carrying out functional analysis, it is essential to proceed to structure the new behavior. It is necessary to think about the routine people should follow, what the routine trigger is, and what consequence and reinforcement will be necessary to transform the new routine into a habit.

When analyzing the new routine, it is important to verify if the operator has the capacity to execute it. Otherwise, job training should be scheduled. However, according Fogg [66], there are two ways to increase human abilities: train people to improve their skills to do the activities or make the 
desired routine easier and simpler to do. When the task is simplified, the skill development becomes fast and easy. The activities to be performed should be analyzed based on the scarcest resources at the moment-time, physical effort, mental effort, or deficient devices-in order to make the routine simpler to prevent require resources that the worker does not have [67].

(iii) Reduce barriers: the leaders have to assume the responsibilities to reduce the communication, credibility and trust, values, inertia and limited rationality barriers. When they know the profile of the team, it is easier to adapt the communication strategies. In a team with an 'analytical or practical' profile, the information should be presented in chronological order, indicating dates for events, deadlines and limits for the projects. However, this would probably be annoying for teams with an 'experimental and relational' profile who prefer a more general approach and with participation and an opportunity to express themselves publicly.

The leader must also be committed to explaining, supporting, and eliminating latent issues that undermine the new routine to overcome credibility and trust barriers. In addition, a sense of urgency should be established for the process with short-term performance targets to surpass the inertia barrier. Finally, the leader should build an emotional connection with the team through recognition, empathy, and future vision.

The third step of the process consists of carry out training in order to internalize the skills. The aim is to achieve learning and a permanent behavior change. In an industrial process, it is important to simplify existent procedures and keep checklists to emphasize the triggers that direct the correct behavior through the document.

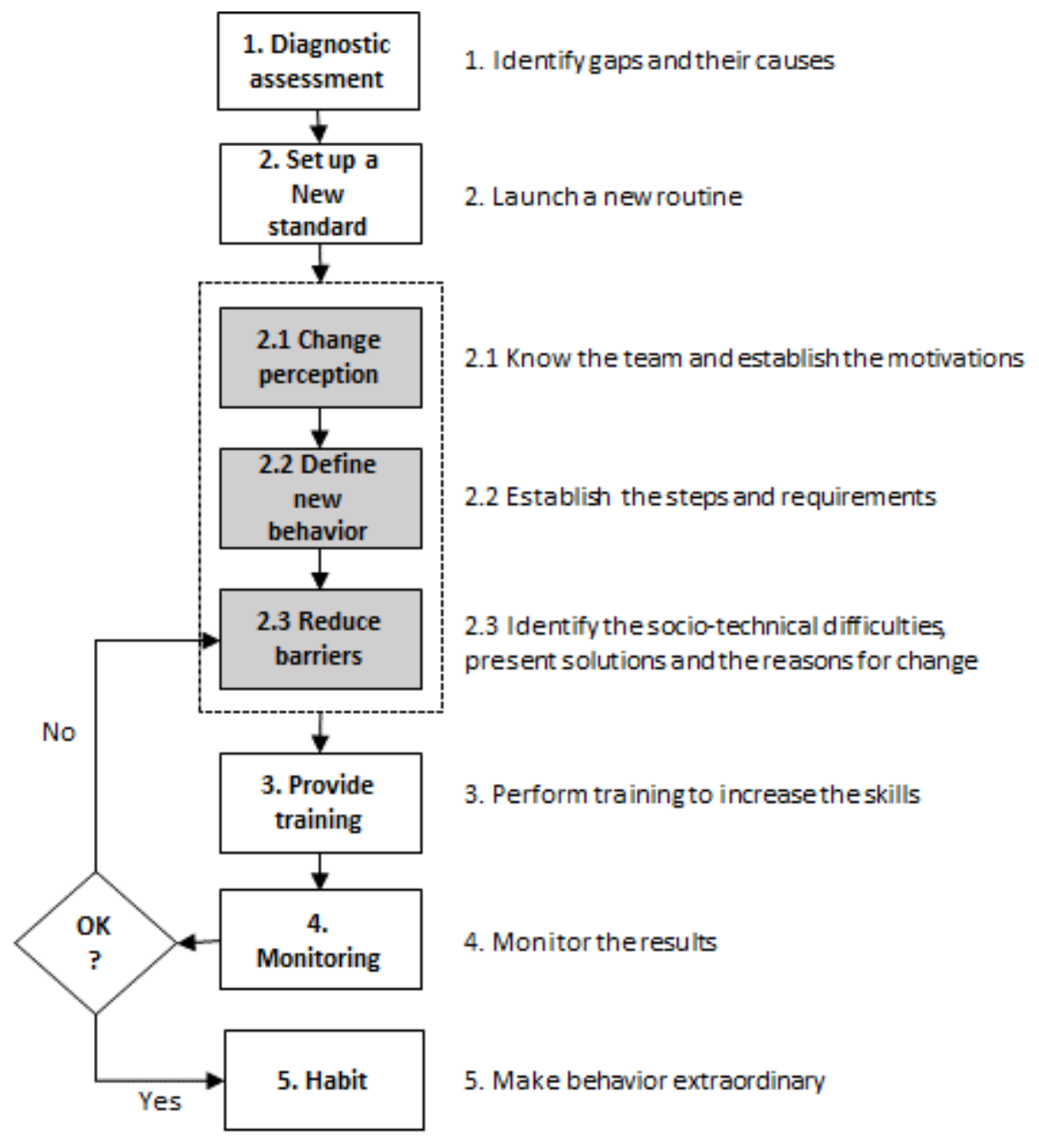

Figure 3. The proposed framework. 
Finally, the last two steps intend to transform the newly learned behavior from the rational mode to the automatic mode, converting the rational behavior into a habit. This is an important point that comes with the assertion that excellence is not to do extraordinary things but to do ordinary things at an extraordinary level, standing out by doing the basics better than anyone else in the market does. At this stage, the leader has to measure and show the results achieved as well as influence the team through the application of actions to reduce barriers. Beyond a supervision support, peer checking in the field is important to the monitoring process since there will be immediate feedback during the task.

The use of this approach has the following advantages:

- It takes into account human behavior and its influence on energy efficiency

- It enables new procedures to become habits and behaviors.

- It contributes to preserving the environment

- The majority of analyzed papers deal with barriers, but not with ways of overcoming them

\section{Results}

The fertilizer industry studied is a urea producer and has two main units as shown in Figure 4: the production of ammonia in unit A and urea in unit B. Ammonia is produced by the reaction of nitrogen from the air and hydrogen, and urea is generated by the reaction between ammonia and carbon dioxide.

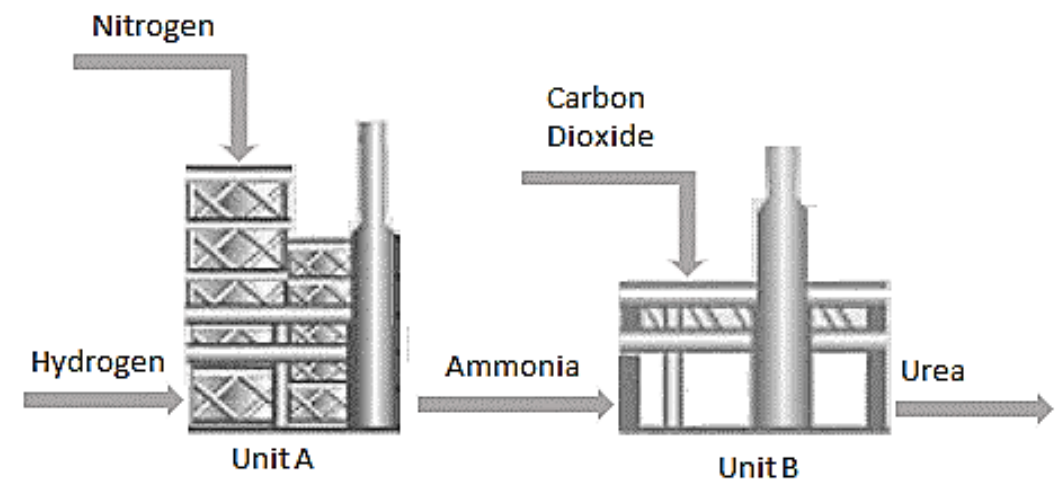

Figure 4. The flowchart of urea production.

There is a drainage of the reactor when production needs to be stopped, because the chemical components are corrosive and can cause damage to the equipment. Thus, 200 tons of the reactive solution and $240 \times 10^{7} \mathrm{~kJ}$ are lost each time the solution is discarded to the stabilization lagoon.

Temporary storage tanks were installed in the area to receive the reactional content for future reprocessing. However, routinely, the content of the tanks was sent to the stabilization lagoon, generating a serious environmental problem and waste of raw material and energy. Thus, the lagoon that should be used eventually to dampen the effects of occasional contaminated effluent had an abnormal use. Besides, there was an increment of contamination loads of ammoniacal nitrogen that caused difficulties to fit the effluent into the standards of legislation. Consequently, the risk of fines increases.

As the company does not have ISO 9001 certification or an effective scheme to control the process standardization, whenever a procedure was changed, it was not adequately monitored, generating a lack of commitment and reduction in operational reliability. Another observed aspect was the lack of cooperation among areas (security, maintenance, operation) that generated a bias in the process of judgement and decision-making.

The project implementation over one year, from 2015 to 2016. They held 12 meetings during the year with specialists from the chemical plant. The brain storm method was used for identifying the 
critical points dealing with energy efficiency and ways to improve factory performance and to avoid energy losses due to human errors.

Decisive factors were examined to suggest improvement actions since they could be barriers to adopt EEI. Aspects were identified such as adoption of unofficial procedures as routine, lack of knowledge regarding technical matters of the operation, fearful operators, and the guilt culture. It was not possible to make a survey; however, worker attitudes were determined through interviews, observation, and reading the shift book.

In order to give the statements called reasons for people to care (RPC) a socio-technical program called "Friends of the Stabilization Lagoon" was proposed to create a connection to the wanted performance and to change the workers' perception of the installed reality. Bulletins were prepared with technical information to be shared and discussed with the shift operators.

As a result of the meetings to discuss the technical information and the application of the $A B C$ analyses, it was found that the operators stopped the reactor and sent its contents to the storage tank whenever there was any problem in the production process. This reactive mixture could be reused within $24 \mathrm{~h}$, which did not routinely happen, since the content of the storage tank was sent to the lagoon due to the delayed decision-making to reprocess. The new procedure was designed based on an old pattern that the entire inventory of the reactors would be sent for completion of the process during the shutdowns. In order to remove behavioral obstacles to adopt the new procedure, since the old pattern was complex with a five-level decision tree, the activities were reviewed to be simpler and easier to do.

The "Friends of the Stabilization Lagoon" program developed innovative explanatory booklets to be used by the leaders in the training of operators to increase their skills and to demonstrate reasons for the procedure changes.

The variable chosen to verify the effectiveness of the program was the effluent concentration of ammoniacal nitrogen $\left(\mathrm{NH}_{3}-\mathrm{N}\right)$, because this variable is strongly influenced by plant shutdowns and their consequent energy and mass losses. Before the implementation of the proposed method, there were peaks of $\mathrm{NH}_{3}-\mathrm{N}$ concentration that exceed the maximum limit allowed by the law and to send effluents for the treatment plant, it was necessary to dilute them. After the implementation of the method, the variation and peaks were reduced, and the level of $\mathrm{NH}_{3}-\mathrm{N}$ concentration was below the allowed limits. As it can be observed in the Figure 5, sometimes the values were above the control limit in the base line period (month 1-4). The calculated mean was $2950\left(\times 10 \mathrm{mg} \cdot \mathrm{L}^{-1}\right)$, and a variation of 644 . From month 5, there was a decrease of $30.6 \%$ in the mean, and $40.5 \%$ in the variation due to behavior change in the way to stop the reactor.

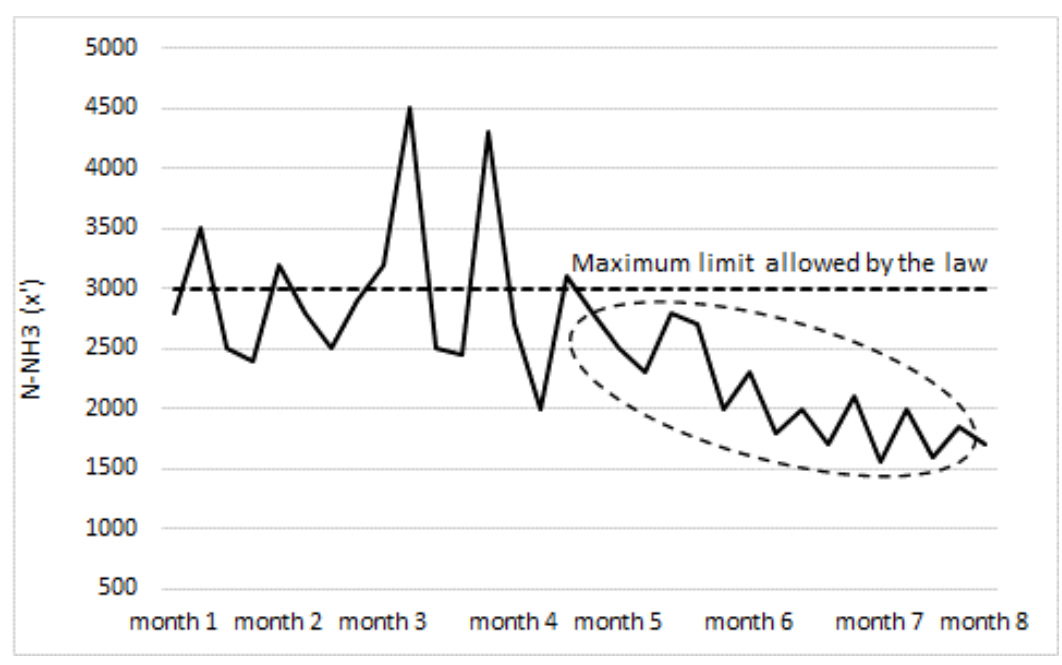

Figure 5. Concentration of ammoniacal nitrogen. 


\section{Discussion}

According to the model, it was possible using appropriate tools in the step-identifying the GAPs-based on document analysis and task observation. This phase is important to avoid defining areas where measurement is difficult or do not affect performance. Critical task/behavior was identified and defined as: send the reactor contents to the storage tank during an unscheduled shutdown of the plant and the discard it into the stabilization lagoon whenever there was delay in its reuse.

In the sub item 'change perception', there was a lack of guiding tools to define the team approach strategy. The model recommends brain preference testing and an attitude survey to have a current picture of employees' willingness to be involved. Statistical analyses can avoid superficial conclusions of the organizational environment. As the use of this tool was not authorized, interviews, observation, and reading of the shift book were used to know the workers' attitudes.

Regarding the sub item, the structure of future behavior, the ABC analysis was important to understand current behavior and plan corrective actions to start the new routine and block old habits. A fundamental aspect recommended by the model is to create the desired routine to make it simpler and easier than the current one by reducing the demand for the resources of the task: time, physical effort, mental effort, and inadequate devices or equipment as stated by [66].

The metaphors and symbols used in the bulletins and booklets made the communication more playful in the sub item 'reduce barriers'. However, the result could have been more effective if the workers' brain profile had been identified to design the communication approach and establish greater emotional links.

The third and fourth step of the model were developed satisfactorily. However, the last step of the conceptual model was not verified in this study. The fifth stage need a continuous monitoring and corrective action when necessary to avoid the return of the old habit, because it remains present and ready to return.

Although the model was initially designed for EEI in industry, the theoretical implications are applicable to any management area (quality, environment or safety). It was noticed that current management systems applied by NIEs companies usually do not take in account the process of internalizing efficiency practices as they fail to understand the human factors. It is common to look at people's performance based on the black-box model of human behavior that focuses primarily on information input and output control. While the conceptual framework incorporates the socio-technical approach and human reliability as themes as well as a set of support tools, it essential to include a statistical model tests, such as correlation and T-tests, to understand the result during the new behavior implementation.

When an organization has a certified management system, there is no guarantee that the potential results that could be achieved by changing technologies and efficiency practices will be achieved. An understanding of the influence of human factors and how to overcome obstacles to improve process performance is fundamental and the proposed conceptual framework aims to fill this gap.

The role played by leaders is critical to the application of the model. Successful management systems mean balancing strategic and routine actions as well as embracing employee involvement. Obviously, it is not feasible to propose a unique and suitable solution for all industries. However, the proposed model can be adjusted.

Finally, there is often a fear among policy makers regarding the achievement of the goals of reducing atmospheric emissions. The extensive use of renewable energy will not be sufficient and intense EEIs are required. On the other hand, just replacing old technologies with new ones does not ensure that they will be automatically adopted. It is here that the use of socio-technical models can greatly support the process. 


\section{Conclusions}

The rise of greenhouse gas emissions and concerns about the use of fossil energy to supply economic growth have prompted industries to implement opportunities to enhance energy efficiency. However, most measures are almost exclusively technology oriented based on engineering solutions (input and output model); consequently, the level of opportunities implemented and what theoretically could be achieved falls short of expectations. It is because the sociotechnical system interactions among people, facilities, and management systems is not taken into account. This paper, therefore, developed a model to help managers to overcome the difficulties through a systematic process in order to implement appropriate procedures and form reliable teams to deal with barriers, human error, and human behaviors. The results of the case study in a fertilizer company showed the potential of the method to improve environmental and energy performance. It was observed that there was a $30.6 \%$ reduction in mass and energy losses.

In line with previous studies, people achieve high levels of performance through the influence of organization processes, values, and reinforcement received from leaders. However, this can be potentiated by using integrated tools to change perceptions, structure future behavior, and reduce the barriers. This paper contributes to the literature in this sense. Moreover, the findings indicate that giving reasons for people to care (RPC) based on metaphor or symbols besides understanding the ABC behavior cycle is fundamental to making habits extraordinary. Applying the tools in an integrated way, the framework constitutes a method for making immeasurable benefits, allowing managers to achieve their targets.

The social-technical framework was developed for EEI in non-intensive energy enterprises. However, it can be used to improve performance in other management systems such as quality, environment, or safety. Despite the model having great potential as shown in the study, additional research applying the all the steps—as well as their associated tools—should be conducted.

Furthermore, the potential of a social-technical approach could go beyond the energy, quality, or safety centric view. These perspectives could be broadened to consider corporate social performance, corporate environmental performance, or corporate sustainability.

Author Contributions: For research José Rafael Lopes performed the literature review, data collecting in the field and analyzed the data; Salvador Ávila and Ricardo Kalid designed the study and verified the results, Jorge Laureano Moya Rodríguez clarified the concepts regarding design method. All authors were involved in preparing and writing the manuscript.

Acknowledgments: The research work has been supported by the Ministry of Education of Brazil under the program for improvement of higher education personnel scholarship. The authors would like to thank to the CNPq Productivity of Research Funds Process 301105/2016-2 and the fertilizer industry for providing personnel time and the information necessary to the research.

Conflicts of Interest: The authors declare no conflict of interest.

\section{References}

1. Trianni, A.; Cagno, E.; Farné, S. Barriers, drivers and decision-making process for industrial energy efficiency: A broad study among manufacturing small and medium-sized enterprises. Appl. Energy 2016, 162, 1537-1551. [CrossRef]

2. Thollander, P.; Paramonova, S.; Cornelis, E.; Kimura, O.; Trianni, A.; Karlsson, M.; Cagno, E.; Morales, I.; Navarro, J.P.J. International study on energy end-use data among industrial SMEs (small and medium-sized enterprises) and energy end-use efficiency improvement opportunities. J. Clean. Prod. 2015, 104, $282-296$. [CrossRef]

3. Sweeney, J.C.; Kresling, J.; Webb, D.; Soutar, G.N.; Mazzarol, T. Energy saving behaviours: Development of a practice-based model. Energy Policy 2013, 61, 71-381. [CrossRef]

4. Paramonova, S.; Thollander, P.; Ottosson, M. Quantifying the extended energy efficiency gap-evidence from Swedish electricity-intensive industries. Renew. Sustain. Energy Rev. 2015, 51, 472-483. [CrossRef] 
5. Blomqvist, E.; Thollander, P. An integrated dataset of energy efficiency measures published as linked open data. Energy Effic. 2015, 8, 1125-1147. [CrossRef]

6. Chiaroni, D.; Chiesa, V.; Franzò, S.; Frattini, F.; Latilla, V.M. Overcoming internal barriers to industrial energy efficiency through energy audit: A case study of a large manufacturing company in the home appliances industry. Clean Technol. Environ. Policy 2017, 19, 1031-1046. [CrossRef]

7. Backman, F. Barriers to energy efficiency in Swedish non-energy-intensive micro-and small-sized enterprises-A case study of a local energy program. Energies 2017, 10, 100. [CrossRef]

8. Chiu, T.-Y.; Lo, S.-L.; Tsai, Y.-Y. Establishing an integration-energy-practice model for improving energy performance indicators in ISO 50001 energy management systems. Energies 2012, 5, 5324-5339. [CrossRef]

9. Hirst, E.; Brown, M. Closing the efficiency gap: Barriers to the efficient use of energy. Resour. Conserv. Recycl. 1990, 3, 267-281. [CrossRef]

10. Sorrell, S.; Schleich, J.; Scott, S.; O'malley, E.; Trace, F.; Boede, U.; Ostertag, K.; Radgen, P. Reducing Barriers to Energy Efficiency in Public and Private Organizations; Science and Policy Technology Research (SPRU), University of Sussex: Sussex, UK, 2000.

11. Cagno, E.; Trianni, A. Evaluating the barriers to specific industrial energy efficiency measures: An exploratory study in small and medium-sized enterprises. J. Clean. Prod. 2014, 82, 70-83. [CrossRef]

12. Häckel, B.; Pfosser, S.; Tränkler, T. Explaining the energy efficiency gap-Expected Utility Theory versus Cumulative Prospect Theory. Energy Policy 2017, 111, 414-426. [CrossRef]

13. Sorrell, S.; Mallett, A.; Nye, S. Barriers to Industrial Energy Efficiency: A literature Review; United Nations Industrial Development Organization (UNIDO): Vienna, Austria, 2011.

14. Thollander, P.; Palm, J.; Rohdin, P. Categorizing barriers to energy efficiency-An interdisciplinary perspective. In Energy Efficiency; InTech: London, UK, 2010.

15. Kee, D.; Jun, G.T.; Waterson, P.; Haslam, R. A systemic analysis of South Korea Sewol ferry accident-Striking a balance between learning and accountability. Appl. Ergon. 2017, 59, 504-516. [CrossRef] [PubMed]

16. Martínez-Espiñeira, R.; García-Valiñas, M.A.; Nauges, C. Households' pro-environmental habits and investments in water and energy consumption: Determinants and relationships. J. Environ. Manag. 2014, 133, 174-183. [CrossRef] [PubMed]

17. Frederiks, E.R.; Stenner, K.; Hobman, E.V. Household energy use: Applying behavioural economics to understand consumer decision-making and behaviour. Renew. Sustain. Energy Rev. 2015, 41, 1385-1394. [CrossRef]

18. Fornara, F.; Pattitoni, P.; Mura, M.; Strazzera, E. Predicting intention to improve household energy efficiency: The role of value-belief-norm theory, normative and informational influence, and specific attitude. J. Environ. Psychol. 2016, 45, 1-10. [CrossRef]

19. Lopes, M.; Antunes, C.; Martins, N. Energy behaviours as promoters of energy efficiency: A 21st century review. Renew. Sustain. Energy Rev. 2012, 16, 4095-4104. [CrossRef]

20. Thollander, P.; Palm, J. Industrial energy management decision making for improved energy efficiency-Strategic system perspectives and situated action in combination. Energies 2015, 8, 5694-5703. [CrossRef]

21. Zhang, G.; Cao, Y.; Cao, Y.; Li, D.; Wang, L. Optimal Energy Management for Microgrids with Combined Heat and Power (CHP) Generation, Energy Storages, and Renewable Energy Sources. Energies 2017, 10, 1288. [CrossRef]

22. Capizzi, G.; Sciuto, G.L.; Napoli, C.; Tramontana, E. Advanced and Adaptive Dispatch for Smart Grids by means of Predictive Models. IEEE Trans. Smart Grid 2017. [CrossRef]

23. Kozhevnikov, M.; Gitelman, L.; Magaril, E.; Magaril, R.; Aristova, A. Risk Reduction Methods for Managing the Development of Regional Electric Power Industry. Sustainability 2017, 9, 2201. [CrossRef]

24. Bonanno, F.; Capizzi, G.; Sciuto, G.L. A neuro wavelet-based approach for short-term load forecasting in integrated generation systems. In Proceedings of the 2013 International Conference on Clean Electrical Power (ICCEP), Alghero, Italy, 11-13 June 2013; pp. 772-776.

25. Rockström, J.; Steffen, W.; Noone, K.; Persson, Å.; Chapin, F.S., III; Lambin, E.; Lenton, T.M.; Scheffer, M.; Folke, C.; Schellnhuber, H.J.; et al. Planetary boundaries: Exploring the safe operating space for humanity. Ecol. Soc. 2009, 14, 33. [CrossRef] 
26. Steffen, W.; Richardson, K.; Rockström, J.; Cornell, S.E.; Fetzer, I.; Bennett, E.M.; Biggs, R.; Carpenter, S.R.; De Vries, W.; de Wit, C.A.; et al. Planetary boundaries: Guiding human development on a changing planet. Science 2015, 347, 1259855. [CrossRef] [PubMed]

27. Fanning, A.L.; O'Neill, D.W. Tracking resource use relative to planetary boundaries in a steady-state framework: A case study of Canada and Spain. Ecol. Indicators 2016, 69, 836-849. [CrossRef]

28. Lomborg, B. Global Warming's Technology Deficit. Available online: https:/ /www.project-syndicate.org/ commentary/global-warming-s-technology-deficit?barrier=accessreg (accessed on 17 December 2017).

29. Bilgili, M.; Ozbek, A.; Sahin, B.; Kahraman, A. An overview of renewable electric power capacity and progress in new technologies in the world. Renew. Sustain. Energy Rev. 2015, 49, 323-334. [CrossRef]

30. Willems, W.; Kramer, U.; Maas, H. Alternative fuels of today for sustainable mobility of tomorrow. In Internationaler Motorenkongress 2017; Springer: Wiesbaden, Germany, 2017; pp. 381-389.

31. Van der Hoeven, M.; Houssin, D. Energy Technology Perspectives 2015: Mobilising Innovation to Accelerate Climate Action; International Energy Agency: Paris, France, 2015.

32. Worrell, E. The next frontier to realize industrial energy efficiency. In Linköping Electronic Conference Proceedings; Linköping University Electronic Press: Linköping, Sweden, 2011; Volume 7, pp. 1-13.

33. Introna, V.; Cesarotti, V.; Benedetti, M.; Biagiotti, S.; Rotunno, R. Energy Management Maturity Model: An organizational tool to foster the continuous reduction of energy consumption in companies. J. Clean. Prod. 2014, 83, 108-117. [CrossRef]

34. Jovanović, B.; Filipović, J. ISO 50001 standard-based energy management maturity model-proposal and validation in industry. J. Clean. Prod. 2016, 112, 2744-2755. [CrossRef]

35. Zobel, T.; Malmgren, C. Evaluating the management system approach for industrial energy efficiency improvements. Energies 2016, 9, 774. [CrossRef]

36. Lee, D.; Cheng, C.-C. Energy savings by energy management systems: A review. Renew. Sustain. Energy Rev. 2016, 56, 760-777. [CrossRef]

37. Saidur, R.; Ahamed, J.; Masjuki, H. Energy, exergy and economic analysis of industrial boilers. Energy Policy 2010, 38, 2188-2197. [CrossRef]

38. Terehovics, E.; Veidenbergs, I.; Blumberga, D. Energy and exergy balance methodology. Wood chip dryer. Energy Procedia 2017, 128, 551-557. [CrossRef]

39. Svensson, E.; Harvey, S. Pinch analysis of a partly integrated pulp and paper mill. In Proceedings of the WREC-World Renewable Energy Congress, Linköping, Sweden, 8-11 May 2011.

40. Stephenson, J.; Barton, B.; Carrington, G.; Doering, A.; Ford, R.; Hopkins, D.; Lawson, R.; McCarthy, A.; Rees, D.; Scott, M.; et al. The energy cultures framework: Exploring the role of norms, practices and material culture in shaping energy behaviour in New Zealand. Energy Res. Soc. Sci. 2015, 7, 117-123. [CrossRef]

41. Bell, M.; Carrington, G.; Lawson, R.; Stephenson, J. Socio-technical barriers to the use of energy-efficient timber drying technology in New Zealand. Energy Policy 2014, 67, 747-755. [CrossRef]

42. Stragier, J.; Hauttekeete, L.; de Marez, L. Reducing Households' Energy Use: A Segmentation of Flanders on Adoption Intention of Smart Metering Technology. In Proceedings of the WREC-World Renewable Energy Congress, Linköping, Sweden, 8-11 May 2011; Volume 3, p. 945.

43. Schulze, M.; Nehler, H.; Ottosson, M.; Thollander, P. Energy management in industry-A systematic review of previous findings and an integrative conceptual framework. J. Clean. Prod. 2016, 112, 3692-3708. [CrossRef]

44. ISO International Organization for Standardization. ISO 50001: Energy Management Systems—Requirements with Guidance for Use, 2011. Available online: http://www.iso.org/standard/51297.html (accessed on 18 October 2017).

45. Bunse, K.; Vodicka, M.; Schönsleben, P.; Brülhart, M.; Ernst, F.O. Integrating energy efficiency performance in production management-gap analysis between industrial needs and scientific literature. J. Clean. Prod. 2011, 19, 667-679. [CrossRef]

46. Thollander, P.; Palm, J. Improving Energy Efficiency in Industrial Energy Systems: An Interdisciplinary Perspective on Barriers, Energy Audits, Energy Management, Policies, and Programs; Springer Science \& Business Media: London, UK; New York, NY, USA, 2012.

47. Fleiter, T.; Schleich, J.; Ravivanpong, P. Adoption of energy-efficiency measures in SMEs-An empirical analysis based on energy audit data from Germany. Energy Policy 2012, 51, 863-875. [CrossRef] 
48. Meath, C.; Linnenluecke, M.; Griffiths, A. Barriers and motivators to the adoption of energy savings measures for small-and medium-sized enterprises (SMEs): The case of the ClimateSmart Business Cluster program. J. Clean. Prod. 2016, 112, 3597-3604. [CrossRef]

49. Backlund, S.; Thollander, P.; Palm, J.; Ottosson, M. Extending the energy efficiency gap. Energy Policy 2012, 51, 392-396. [CrossRef]

50. Nehler, T.; Rasmussen, J. How do firms consider non-energy benefits? Empirical findings on energy-efficiency investments in Swedish industry. J. Clean. Prod. 2016, 113, 472-482. [CrossRef]

51. Thollander, P.; Danestig, M.; Rohdin, P. Energy policies for increased industrial energy efficiency: Evaluation of a local energy programme for manufacturing SMEs. Energy Policy 2007, 35, 5774-5783. [CrossRef]

52. Trist, E.L.; Higgin, G.W.; Murray, H.; Pollock, A.B. Organizational Choice; Routledge: Oxfordshire, UK, 2013.

53. Balbinotti, G.; Paupitz, A. Internationally management of socio-technical projects-A case study in a vehicle assembly. Procedia Manuf. 2015, 3, 6345-6352. [CrossRef]

54. Bostrom, R.P.; Heinen, J.S. MIS problems and failures: A socio-technical perspective, part II: The application of socio-technical theory. MIS Q. 1977, 1, 11-28. [CrossRef]

55. Akyuz, E.; Celik, M. Application of CREAM human reliability model to cargo loading process of LPG tankers. J. Loss Prev. Process Ind. 2015, 34, 39-48. [CrossRef]

56. Reason, J. Human Error; Cambridge University Press: Cambridge, UK, 1990.

57. Embrey, D.; Kontogiannis, T.; Green, M. Guidelines for Preventing Human Error in Process Safety; Center for Chemical Process Safety: New York, NY, USA, 1994; Volume 1.

58. McLeod, R.W. Human factors in barrier management: Hard truths and challenges. Process Saf. Environ. Prot. 2017, 110, 31-42. [CrossRef]

59. Robbins, S.P.; Judge, T.A.; Vohra, N. Organizational Behaviour, 15th ed.; Pearson Education, Inc.: Upper Saddle River, NJ, USA, 2013.

60. Wickens, C.D.; Hollands, J.G.; Banbury, S.; Parasuraman, R. Engineering Psychology E Human Performance; Psychology Press: East Sussex, UK, 2015.

61. Swain, A.D.; Guttmann, H.E. Handbook of Human-Reliability Analysis with Emphasis on Nuclear Power Plant Applications; Final Report; Sandia National Labs.: Albuquerque, NM, USA, 1983.

62. Hollnagel, E. Cognitive Reliability and Error Analysis Method (CREAM); Elsevier: New York, NY, USA, 1998.

63. Robbins, S.P.; Judge, T.A.; Millett, B. OB: The Essentials; Pearson Higher Education AU: Jersey City, NJ, USA, 2015.

64. Herrmann, N. The creative brain. J. Creat. Behav. 1991, 25, 275-295. [CrossRef]

65. Daniels, A.C.; Tapscott, D.; Caston, A. Bringing out the Best in People; Findaway World LLC: Solon, OH, USA, 2011.

66. Fogg, B.J. A behavior model for persuasive design. In Proceedings of the 4 th International Conference on Persuasive Technology, Claremont, CA, USA, 26-29 April 2009; ACM: New York, NY, USA, 2009; p. 40.

67. Fogg, B.J. Fogg Behavior Model. Available online: http://behaviormodel.org/index.html (accessed on 18 December 2016).

(C) 2018 by the authors. Licensee MDPI, Basel, Switzerland. This article is an open access article distributed under the terms and conditions of the Creative Commons Attribution (CC BY) license (http:/ / creativecommons.org/licenses/by/4.0/). 